\title{
OBTENÇÃo DE TITÂNIO METÁLICO COM POROSIDADE CONTROLADA POR METALURGIA DO PÓ
}

\section{Neila de Almeida Braga* e Neidenêi Gomes Ferreira}

Laboratório Associado de Sensores e Materiais, Instituto Nacional de Pesquisas Espaciais, Av. dos Astronautas, 1758, $12227-$ 010 São José dos Campos - SP, Brasil

Carlos Alberto Alves Cairo

Divisão de Materiais, Instituto de Aeronáutica e Espaço, Centro Técnico Aeroespacial, Pr. Mal. Eduardo Gomes, 50, 12228-904 São José dos Campos - SP, Brasil

Recebido em 11/11/05; aceito em 31/5/06; publicado na web em 28/11/06

\begin{abstract}
POROUS TITANIUM PRODUCTION AND POROSITY CONTROL BY POWDER METALLURGY (P/M). Titanium is an attractive material for structural and biomedical applications because of its excellent corrosion resistance, biocompatibility and high strengthto-weight ratio. The high reactivity of titanium in the liquid phase makes it difficult to produce it by fusion. Powder metallurgy has been shown to be an adequate technique to obtain titanium samples at low temperatures and solid-phase consolidation. The production of compacts with different porosities obtained by uniaxial pressing and vacuum sintering is briefly reviewed. Powder particle size control has been shown to be very important for porosity control. Sample characterization was made using scanning electron microscopy (SEM) images.
\end{abstract}

Keywords: titanium; powder-metallurgy; porous.

\section{INTRODUÇÃO}

\section{Considerações gerais sobre o Ti}

Descoberto como elemento químico em 1791 por W. Gregor ${ }^{1}$ no minério da ilmenita $\left(\mathrm{FeTiO}_{3}\right)$, o titânio é um elemento de transição que apresenta excelentes propriedades físicas ${ }^{2-4}$, dentre as quais se destacam o elevado ponto de fusão ${ }^{5}\left(1668^{\circ} \mathrm{C}\right)$, o ponto de ebulição $\left(3287{ }^{\circ} \mathrm{C}\right)$, a baixa massa específica $\left(4,54 \mathrm{~g} \mathrm{~cm}^{-3}\right)$ e o módulo de tensão de elasticidade (acima de $12,7 \times 10^{4} \mathrm{MPa}$ ). Destas propriedades, destacam-se a massa específica e o módulo de tensão de elasticidade. A maioria dos aços apresentam massa específica em torno de 7,87 $\left.\mathrm{g} \mathrm{cm}^{-3}\right]^{5}$, ou seja, o dobro da massa específica do titânio; somando-se a isto, tem-se o fato de que as propriedades mecânicas do titânio podem ser melhores que as das referidas ligas, visto que o mesmo apresenta tensão específica e rigidez muito altas. Pelo fato do módulo de elasticidade do titânio ser muito maior que de outros metais leves, como $\mathrm{Mg}$ e $\mathrm{Al}$, o mesmo compete com estes para aplicações estruturais espaciais e nanoaeroespaciais ${ }^{6-11}$, uma vez que seu ponto de fusão é muito maior. $\mathrm{O} \mathrm{Mg}$, por ex., não pode ser usado acima de $121{ }^{\circ} \mathrm{C}$, enquanto que o Ti pode ser usado sob temperaturas de até $426^{\circ} \mathrm{C}$ no ar. Temperaturas maiores que esta provocam sua fragilização pelo oxigênio do ar.

Dentre as propriedades químicas, destaca-se a alta reatividade deste metal, o que constitui uma desvantagem no seu processamento $^{12,13}$. O titânio combina-se muito facilmente com outros elementos, principalmente gases como nitrogênio e oxigênio, os quais dissolvem rapidamente no metal líquido ou sólido acima de aproximadamente $400{ }^{\circ} \mathrm{C}$, provocando a perda de ductilidade deste. Como consequiência desta alta reatividade frente a gases, é comumente encontrado na crosta terrestre sob a forma de dióxido de titânio $\mathrm{TiO}_{2}$, chamado rutilo, na concentração de $0,6 \%$ sendo, com isso, o quarto elemento mais abundante dentre os metais estruturais, ficando atrás apenas de $\mathrm{Al}, \mathrm{Fe}$ e $\mathrm{Mg}$. Em relação aos metais, o titânio apresenta

*e-mail: neila@las.inpe.br limitada solubilidade com estes, mas tem uma forte tendência a se combinar formando compostos intermetálicos frágeis.

O titânio apresenta alotropia ${ }^{1}$. À temperatura ambiente, tem uma estrutura cristalina hexagonal compacta, chamada de fase alfa, a qual é estável até $882^{\circ} \mathrm{C}$; acima desta temperatura a estrutura muda para cúbica de corpo centrado, um alótropo chamado de fase beta. $\mathrm{O}$ titânio alfa é o titânio puro ou o titânio cuja tensão é aumentada pela adição de pequenas quantidades de elementos estabilizadores desta fase, como $\mathrm{Al}, \mathrm{Sn}, \mathrm{Ni}$ e $\mathrm{Cu}$. As ligas nas quais este elemento apresenta estrutura alfa não têm sua dureza aumentada com o resfriamento, mas têm maior tensão que o Ti puro comercial. Ligas $\alpha-\beta$ são ligas de Ti com estrutura parcialmente $\alpha$ e parcialmente $\beta$. Elementos como Mo, V e $\mathrm{Ta}$, quando adicionados ao Ti puro à temperatura ambiente, tendem a promover a presença da fase $\beta$. Uma liga importante do ponto de vista industrial é a Ti-6Al-4V, a qual contêm $6 \%$ de $\mathrm{Al}$ e $4 \%$ de $\mathrm{V}$ e apresenta as duas fases estruturais (cerca de $50 \%$ de $\alpha$ e $50 \%$ de $\beta$ ). Elementos como o Mo e V são estabilizadores das ligas $\beta$, as quais são produzidas pela adição de grandes quantidades destes. As ligas $\beta$ têm boa ductilidade e maleabilidade quando não sofrem tratamento térmico.

Outra propriedade química muito importante é a elevada resistência à corrosão. O Ti e suas ligas têm excelente resistência à corrosão em água do mar e em soluções aquosas de cloretos. A maior parte das ligas é resistente a uma grande variedade de meios oxidantes como $\mathrm{HNO}_{3}$ e agentes redutores como $\mathrm{HCl} \mathrm{e} \mathrm{H}_{2} \mathrm{SO}_{4}$, quando estes se encontram diluídos. O titânio é, ainda, resistente à maior parte dos ácidos orgânicos.

O titânio não é tóxico, mas apesar de fisiologicamente inerte, o pó é carcinogênico. Outra conseqüência importante da sua atoxidade é a grande utilização deste metal e suas ligas como biomaterial ${ }^{14-25}$, devido à excelente resistência à corrosão, alta força específica e biocompatibilidade.

\section{OBTENÇÃO DE METAIS POROSOS VIA FASE LÍQUIDA}

Um dos métodos de obtenção de materiais metálicos porosos com alta massa específica é o processo $\mathrm{GASAR}^{26}$, no qual o metal 
líquido é resfriado no ponto eutético, sob atmosfera de hidrogênio, produzindo o gás como uma fase separada no interior do metal. Vários metais porosos podem ser obtidos por este método: níquel, cobre, magnésio, alumínio, molibdênio, berílio, cobalto, crômio, tungstênio, bronze, aço e aço inoxidável. Os materiais produzidos por este método apresentam matriz monolítica ${ }^{27}$ sólida (sem microporosidade), poros com forma geométrica globular, contornos de grão puros e baixa concentração de partículas de não-metais, o que lhes confere melhores tensão, plasticidade e condutividades térmicas e elétricas, quando comparados aos materiais porosos obtidos por outras técnicas, nas quais o grau de microporosidade é elevado ou há a adição de não-metais. Dentre as aplicações das esponjas obtidas pelo método GASAR, destacam-se suporte para filtros, células combustíveis, separadores fluido/partícula, difusores de gases, trocadores de calor, geradores para motores térmicos, matrizes para compósitos, estrutura de painéis de alta tensão e eletrodos porosos, entre outros.

A adição de um agente formador de bolhas a um metal fundido, constitui um método alternativo para a obtenção de materiais metálicos porosos. Neste processo, uma mistura de hidreto metálico e metal fundido, por ex., é compactada e aquecida até o ponto de fusão do metal. A decomposição do hidreto origina a formação e liberação de gás ${ }^{28,29}$. Com a expansão do gás é formada uma estrutura esponjosa, a qual é solidificada por resfriamento. A agitação mecânica de uma mistura de alumínio líquido e carbeto de silício particulado forma uma espuma que, ao ser resfriada, origina a esponja de alumínio. Os processos anteriormente citados apresentam a desvantagem de formarem, em sua maioria, materiais porosos com estrutura celular fechada.

Esponjas metálicas que apresentam estrutura celular aberta podem ser formadas por infiltração de grânulos de material orgânico, inorgânico ou polimérico, os quais podem ser retirados da estrutura metálica por queima ou lixiviação, deixando vazios correspondentes ao espaço ocupado pelos grânulos. Uma outra possibilidade de obtenção de estruturas com porosidade aberta consiste em recobrir um substrato esponjoso polimérico com o metal, usando eletrodeposição. Um exemplo é a obtenção de esponja metálica de níquel por eletrodeposição em poliuretano ${ }^{30}$. Após a eletrodeposição, é feita a pirólise do material, a fim de se eliminar o poliuretano, e a sinterização, para a consolidação da esponja.

Devido às propriedades anteriormente discutidas, o titânio é caro para se produzir, fabricar, usinar e, sobretudo, difícil de ser obtido por processamento via fase líquida. A metalurgia do pó ${ }^{31-34}$ constitui uma técnica na qual todas estas dificuldades podem ser diluídas, produzindo-se titânio volumétrico a temperaturas mais baixas e sob condições que permitam consolidar o metal ainda na fase sólida, minimizando os problemas referentes à sua elevada reatividade química. Os custos podem ser reduzidos através da utilização de técnicas conhecidas como "near-net shape"35-38, ou seja, produção de peças e artefatos deste metal com formato final próximo ao desejado.

\section{A METALURGiA DO PÓ}

A metalurgia do pó é a técnica utilizada para produzir compostos metálicos ou cerâmicos através da produção do pó e de sua consolidação pela aplicação de pressão e calor sob temperaturas abaixo do ponto de fusão do constituinte majoritário. As etapas de processamento de um material metálico por esta técnica envolvem, entre outras, a obtenção e moagem do pó, bem como a conformação e sinterização de peças a partir do mesmo.

O pó pode ser obtido por métodos físicos e/ou químicos. Dentre os métodos químicos, podem ser citados a redução de óxidos - processo baseado no equilíbrio de reações de redução que utilizam como agente redutor hidrogênio, monóxido de carbono e carbono; o processo hidrometalúrgico - consiste na lixiviação do minério, seguido da precipitação do metal na solução. A precipitação pode ocorrer de forma direta por eletrólise, cementação, redução química ou indireta por precipitação de hidróxidos, carbonatos e oxalatos, entre outros; a decomposição térmica de carbonilas - processo no qual as carbonilas são obtidas pela reação do metal com monóxido de carbono sob pressões e temperaturas específicas e, logo após, aquecidas para originarem o metal, através de decomposição; a hidretação metálica - neste processo, o metal é hidrogenado, moído e deidretado sob vácuo e altas temperaturas e, a atomização - processo físico bastante disseminado, que consiste na quebra de um líquido em pequenas gotas com diâmetros menores que $150 \mu \mathrm{m}$. Para tanto, é necessário que um fluxo "perturbador" entre em processo de colisão com o metal fundido. Da colisão entre estes, formam-se as gotículas que se transformam em pó por rápido resfriamento. Dependendo de que meio ou processo é utilizado para a produção das gotículas, a atomização pode ser classificada em: atomização gasosa, atomização em água, por centrifugação e a vácuo, entre outros.

Os aspectos relevantes concernentes à obtenção do pó são o tamanho médio das partículas do pó, a morfologia e composição química das referidas partículas e as microestruturas obtidas. Em sequiência à obtenção do pó, ocorre o processo de moagem, no qual forças de impacto, atrito, cisalhamento e compressão atuam sobre as partículas metálicas maiores, para promoverem a quebra destas, por processos como microforjamento, fratura, aglomeração e desaglomeração, diminuindo o tamanho médio de partículas. Após a moagem, segue-se a etapa de conformação, baseada na compactação ou prensagem do pó contido no interior de uma matriz rígida ou de um molde flexível através da aplicação de pressão ${ }^{39,40}$.

Os dois tipos básicos de prensagem são a uniaxial e a isostática. Na prensagem uniaxial, a compactação do pó é realizada em uma matriz rígida, por aplicação de pressão na direção axial, através de punções rígidos. É utilizada para conformar peças que não apresentam relêvo superficial na direção de prensagem. Na prensagem isostática, a compactação do pó se dá no interior de um molde flexível, sobre o qual atua um fluido pressurizado. Este procedimento assegura uma distribuição homogênea da pressão sobre a superfície do molde. É empregada na fabricação de peças com formato complexo que apresentam relêvos em duas ou mais direções, ou em peças nas quais uma das dimensões é muito maior que as demais, como no caso de tubos e barras.

Dentre os fatores que afetam o empacotamento de partículas ${ }^{41}$, destacam-se: a distribuição granulométrica do pó - empacotamentos com menor porosidade podem ser obtidos se os vazios existentes entre as partículas nas monodispersões forem preenchidos por partículas menores que os mesmos. Geralmente a densidade se eleva com o valor do quociente entre os tamanhos (diâmetros) das partículas maiores e os das menores; a morfologia das partículas - quanto mais afastada do formato esférico for a partícula, menor é a densidade de empacotamento de uma distribuição que a contenha. Isso ocorre devido à fricção interparticular, que surge pelo contato das superfícies irregulares das mesmas. Quanto menor for o tamanho das partículas irregulares, maior será este efeito, devido à maior área superficial específica. Através do controle de distribuição granulométrica, é possível otimizar a densidade de empacotamento em sistemas compostos por partículas não-esféricas; a porosidade das partículas - para se obter um empacotamento de máxima densidade para uma dada distribuição granulométrica, é preciso que se utilizem partículas densas e com a menor porosidade possível e, técnicas de compactação - através da compactação isostática, podese obter compactos muito mais densos que pela técnica de compactação uniaxial. 
A compactação é uma etapa importantíssima na técnica da metalurgia do pó, contudo, a etapa seguinte, sinterização, é determinante das propriedades do material, uma vez que é através desta que são determinadas as microestruturas do material.

A sinterização é um processo de consolidação por queima (na presença ou não de oxigênio), na qual as partículas do pó são unidas formando agregados de alta resistência mecânica. Como consequiência, tem-se a diminuição da porosidade da peça e o aumento da densificação. A sinterização ocorre a partir de 1/2 a 2/3 da temperatura de fusão, o suficiente para causar difusão atômica ou fluxo viscoso. A força motriz para a sinterização é a redução da área superficial (e da energia superficial) obtida pela substituição de um pó solto, cujas superfícies têm alta energia (sólido-vapor), por um sólido ligado, cujos contornos de grão apresentam energia mais baixa.

A transferência de massa durante a sinterização se dá pelos seguintes mecanismos: a sinterização pode ser resultado de um escoamento viscoso ou plástico; a difusão atômica pode ocorrer não somente ao longo dos contornos de grão, ou entre as partículas, mas também no interior dos grãos; materiais voláteis evaporam nas superfícies convexas das partículas e se condensam nas superfícies côncavas de outras, devido aos diferenciais pressão-vapor e, a energia superficial do sólido no líquido é maior nas superfícies convexas que nas côncavas. Portanto, a sinterização na fase líquida provoca uma redução na energia superficial.

Durante a sinterização do titânio ${ }^{42-45}$ é comum o uso de alto vácuo. Este procedimento é necessário devido à formação de uma camada de óxido superficial que, apesar de inicialmente ser dissolvida, pode surgir novamente devido à já comentada alta reatividade deste metal.

Apesar do uso da sinterização a vácuo ser o método mais amplamente utilizado pode-se, alternativamente, utilizar argônio purificado para a sinterização. A densificação em argônio é um pouco menor que no vácuo. $\mathrm{O}$ forno utilizado para a sinterização, além de permitir a entrada de gás inerte para experimentos nos quais a mesma é requerida, funciona com uma bomba de difusão gasosa, podendo-se estabelecer um conjunto de bombas que permita serem atingidos vácuo de até $10^{-7}$ Torr a temperaturas de picos. Em alguns casos, são utilizados "traps" frios para condensar o cloreto de sódio vaporizado oriundo do titânio obtido nos processos Kroll ou Hunter (descritos posteriormente) e outras impurezas, que podem impedir a performance da bomba de difusão.

Os finos de esponjas de titânio puro (pós com 100- mesh), podem ser sinterizados a temperaturas em torno de $1000^{\circ} \mathrm{C}$. A adição de elementos de liga faz com que as temperaturas subam para valores entre 1200 e $1700{ }^{\circ} \mathrm{C}$, a fim de permitir a completa interdifusão e, assim, obterem-se as características desejadas.

Pelo fato das velocidades de difusão serem altas, na região da fase $\beta$, a sinterização é geralmente feita a temperaturas maiores que $880^{\circ} \mathrm{C}$. A microestrutura que surge após lento resfriamento é a microestrutura beta transformada, a qual é considerada uma estrutura inferior àquelas obtidas por materiais trabalhados convencionalmente. Esta limitação não é significativa para peças obtidas a partir de titânio puro comercial porque a tensão estática e a resistência à corrosão são mais importantes. Somente propriedades relacionadas à fadiga e à tenacidade à fratura são afetadas por esta microestrutura.

\section{OBTENÇÃo DE TITÂNIO METÁLICO NO CTA}

Em 1965, o processo Kroll foi adotado como método de obtenção de titânio metálico puro na Divisão de Materiais (AMR) do Centro Técnico Aeroespacial (CTA). Na ocasião, foi criado o Grupo de Processos Metalúrgicos (GPM) com o objetivo de desenvol- ver ligas metálicas reativas, como as constituídas pelos metais titânio e zircônio. O chamado Projeto Titânio ${ }^{46}$, desenvolvido no período de 1965 a 1990, tinha como uma de suas principais metas reduzir o atraso da pesquisa brasileira em relação aos países mais desenvolvidos no que se referia à área de obtenção e processamento de metais. A importância do Projeto Titânio para o Brasil deve-se, entre outros, à aquisição de larga experiência referente ao titânio, cujo conhecimento e domínio das técnicas de produção e transformação são estratégicos para o processo de industrialização de um país, uma vez que o mesmo encontra vasta aplicação nas indústrias aeronáutica, naval, química e petroquímica.

Vale ressaltar que o Projeto Titânio propiciou, na época, o uso de equipamentos ainda não utilizados até então na metalurgia brasileira como, por ex., fornos a vácuo para trabalho à alta temperatura, equipamentos para fusão por indução a vácuo e refusão por escória, entre outros. A contribuição mais importante desse processo foi tornar o Brasil o único país da América Latina auto-suficiente na produção de esponjas de titânio.

Assim, em 1968, foi inaugurada uma usina piloto cujo projeto foi fundamentado em estudos divulgados pelo Bureau of Mines, dos Estados Unidos, e consistiu na adaptação do processo às condições nacionais. Utilizando $\mathrm{TiCl}_{4}$ fabricado comercialmente no Brasil como matéria-prima, a usina piloto era constituída de uma unidade de purificação do $\mathrm{TiCl}_{4}$, uma unidade de redução deste pelo magnésio em atmosfera inerte, uma unidade de destilação a vácuo para a purificação da esponja de titânio pela evaporação e condensação dos vapores de magnésio e do cloreto de magnésio retidos na esponja, e uma divisão de vacuometria, responsável por compactar os fragmentos de esponjas de titânio obtendo pastilhas. Estas pastilhas eram unidas por solda em atmosfera inerte, formando eletrodos consumíveis. Tais eletrodos eram fundidos, sob vácuo, em forno a arco originando os lingotes.

A esponja de titânio assim produzida na usina piloto da AMR, enquadrava-se nas normas internacionais. Toda a tecnologia desenvolvida nesta divisão foi transferida para a iniciativa privada (na época brasileira) e, em 20/11 de 1987, foram encerrados os trabalhos de obtenção de esponjas de titânio no CTA. A esponja utilizada ainda hoje na AMR provém deste período e foi obtida pelo processo $\mathrm{Krool}^{47}$, o qual se constitui um dos métodos mais difundidos de obtenção de titânio puro em pó. Neste processo, o rutilo natural ou sintético é clorado na presença de carbono formando o $\mathrm{TiCl}_{4}$, como mostrado na reação

$\mathrm{TiO}_{2}(\mathrm{~s})+2 \mathrm{Cl}_{2}(\mathrm{~g})+2 \mathrm{C}(\mathrm{s}) \rightarrow \mathrm{TiCl}_{4}(\mathrm{~g})+2 \mathrm{CO}(\mathrm{g})$

O tetracloreto de titânio obtido é purificado por destilação e tratamento químico e é, então, reduzido a titânio metálico (chamado esponja devido à sua aparência). O processo desenvolvido por Krool, em 1946, emprega como agente redutor o magnésio metálico fundido, enquanto que o processo desenvolvido por Hunter ${ }^{48,49}$, em 1910, usa como agente redutor o sódio metálico. Estes processos são quimicamente similares, diferindo apenas em detalhes operacionais, sendo as reações básicas:

Redução do $\mathrm{TiCl}_{4}$ a Ti metálico (etapa realizada no CTA em um reator com uma carga de $\mathrm{Mg}$ em barras, a qual é aquecida a $750{ }^{\circ} \mathrm{C}$, para posterior adição do $\mathrm{TiCl}_{4}$ ):

$\mathrm{TiO}_{2}(\mathrm{~s})+2 \mathrm{Cl}_{2}(\mathrm{~g})+2 \mathrm{C}(\mathrm{s}) \rightarrow \mathrm{TiCl}_{4}(\mathrm{~g})+2 \mathrm{CO}(\mathrm{g})$
$4 \mathrm{Na}(\mathrm{l})+\mathrm{TiCl}_{4}(\mathrm{l}) \rightarrow \mathrm{Ti}(\mathrm{s})+4 \mathrm{NaCl}(\mathrm{s})$
$2 \mathrm{Mg}(\mathrm{s})+\mathrm{TiCl}_{4}(\mathrm{l}) \rightarrow \mathrm{Ti}(\mathrm{s})+2 \mathrm{MgCl}_{2}(\mathrm{~s})$

No processo Hunter, o passo inicial envolve apenas uma redução parcial, seguida de uma segunda redução para completar a reação. 
$2 \mathrm{Na}(\mathrm{l})+\mathrm{TiCl}_{4}(\mathrm{l}) \rightarrow \mathrm{TiCl}_{2} .2 \mathrm{NaCl}(\mathrm{s})$

$2 \mathrm{Na}(\mathrm{l})+\mathrm{TiCl}_{2} .2 \mathrm{NaCl}(\mathrm{s}) \mathrm{TiCl}_{4}(\mathrm{l}) \rightarrow \mathrm{Ti}(\mathrm{s})+4 \mathrm{NaCl}(\mathrm{s})$

O processamento exige que toda a reação seja desenvolvida sob atmosfera inerte (hélio ou argônio), devido à grande reatividade do titânio frente aos gases atmosféricos, os quais podem contaminar o produto final. As temperaturas finais devem ser elevadas a fim de se obter reação completa e partículas esponjosas grossas. No processamento realizado no CTA, o cloreto de magnésio fundido, que é vazado durante a operação, é reciclado por eletrólise originando magnésio e cloro, os quais são reaproveitados no processo. Como a esponja contém em seu interior $\mathrm{Mg}$ e $\mathrm{MgCl}_{2}$, após o resfriamento, é levada para a retorta de destilação a vácuo para retirada do sal residual.

O tamanho das partículas é controlado por procedimentos operacionais e corte. Dependendo da finalidade de uso, pode variar de pedaços grossos até pó. Uma vez obtido o pó por este método, segue-se o processamento do mesmo para ajuste e adequação do tamanho de partículas, o que é geralmente feito pelo método $\mathrm{HDH}$.

\section{OBTENÇÃO DE TITÂNIO POR METALURGIA DO PÓ NO CTA}

Com a finalização das pesquisas envolvendo titânio no CTA, em 1995, a metalurgia do pó foi adotada como uma alternativa viável para a obtenção de titânio e suas ligas, em virtude das maiores facilidades operacionais que permeiam a técnica. A pesquisa que originou o presente trabalho tem utilizado esta técnica com o objetivo de obter compactos de titânio puro com porosidade controlada e de estudar o efeito da morfologia e do tamanho médio de partículas na obtenção dos mesmos.

Como o titânio puro e suas ligas são geralmente pouco dúcteis e, por este motivo, não podem ser transformados em pó por cominuição (moagem), é necessária uma alternativa para reduzir o tamanho das partículas do pó. Pode-se hidrogenar o metal em um processo conhecido como Hidreto-Deidreto ${ }^{38}$, uma vez que o titânio reage com o hidrogênio para formar hidretos, os quais são frágeis, tornando a cominuição fácil. A hidrogenação requer equipamentos especiais, já que a reação é extremamente exotérmica. O forno de alto vácuo tipo Astro utilizado no CTA/AMR, trabalha com um conjunto de bombas que permitem obter um vácuo de até $10^{-7} \mathrm{Torr}$ para a hidrogenação dos finos de esponjas. Este forno foi utilizado para fragilizar $300 \mathrm{~g}$ do pó de titânio obtido pelo processo Kroll, com os seguintes parâmetros experimentais: temperatura do início da reação de $680^{\circ} \mathrm{C}$, pressão de $0,07 \mathrm{MPa}$ e tempo de hidrogenação de $1 \mathrm{~h}$. Após a hidrogenação o titânio fica fragilizado, facilitando o processo de moagem controlada. A Figura 1 mostra a imagem obtida por microscopia eletrônica de varredura (MEV) das partículas do pó obtido por este processo. As superfícies das partículas apresentam porosidade e rugosidade decorrentes do processo de deidrogenação. O formato angular apresentado por estas partículas constitui-se em uma desvantagem para a fluidez no momento de deposição do pó nas cavidades do molde utilizado para a compactação, uma vez que o fluxo é restringido devido às pontes formadas entre as partículas angulares; como consequiência, a densidade de empacotamento é baixa e menos consistente quando comparada ao empacotamento de partículas esféricas. Entretanto, para a obtenção de substratos porosos, o pó, assim obtido, mostra-se ideal, já que a baixa densidade de empacotamento deve contribuir para a formação de maior porosidade residual.

O pó fragilizado pode ser moído, a fim de se selecionar por peneiração as faixas granulométricas com as quais se deseja trabalhar. No caso do titânio, foram utilizados para este fim, um moinho com estrutura do mesmo metal e meios de moagem esféricos em

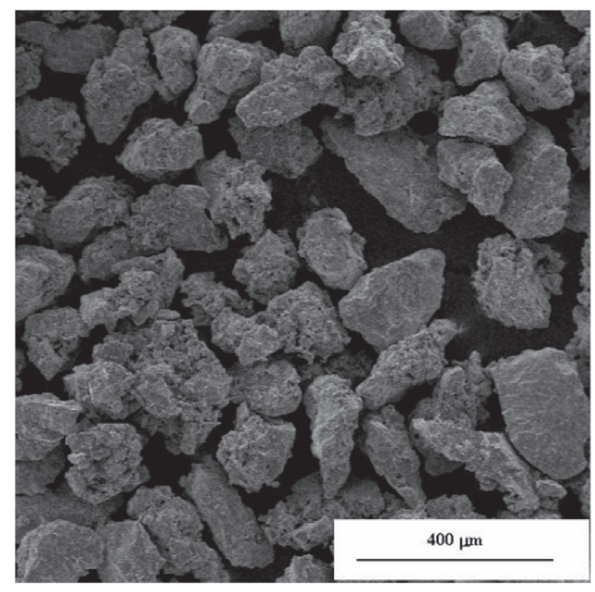

Figura 1. Imagem $M E V$ do pó de titânio puro hidrogenado obtido no CTA pelo processo Krool e fragilizado pela técnica $\mathrm{HDH}$. $100 \mathrm{X}$

titânio evitando, assim, a contaminação do titânio com elementos provenientes das partes do moinho. O tamanho de partículas que se deseja obter é função dos parâmetros de moagem. Dentre os principais parâmetros de moagem, destacam-se o tamanho inicial das partículas do pó, a relação carga (pó)/meios de moagem, a densidade e o tamanho dos meios de moagem, a velocidade de rotação do moinho, as características mecânicas do pó inicial (se deforma fragilmente ou ductilmente, por ex.) e o tempo de moagem. Neste caso, foi utilizado um tempo de $30 \mathrm{~min}$ de moagem, que se mostrou suficiente para a obtenção do tamanho médio de partículas esperado.

Uma vez obtido o pó e fragilizado, os métodos de obtenção do titânio poroso por metalurgia do pó diferem entre si em detalhes de processamento. Para os processos baseados na sinterização do pó, destacam-se os descritos a seguir.

\section{SINTERIZAÇÃO DE PRÉ-FORMAS}

Para se obter compactos de titânio com máxima densificação, geralmente são empregadas sinterizações de pré-formas compactadas a pressões superiores a $415 \mathrm{MPa}^{38}$. Nestes casos, são obtidas densidades a verde (densidades antes da sinterização) entre 85 a $90 \%$. posterior sinterização combinada com aplicação de pressão isostática pode elevar a densificação para valores entre 95 e 99,5\%. A sinterização de pré-formas é importante, pois provê uma melhoria nas propriedades mecânicas dos compactos em relação à sinterização do pó livre, mas para se obter a porosidade desejada no metal fazse, então, necessário trabalhar com as menores pressões de compactação possíveis. Ricceri et al. ${ }^{50}$, utilizando compactação isostática, destacam a variação da porosidade como função das pressões de compactação. Assim, quanto menor for a pressão, maior será a porosidade, existindo um limite, uma vez que não foi possível obter compactos para pressões inferiores a $50 \mathrm{MPa}$.

Outro aspecto importante é ter o domínio da forma e faixa granulométrica do pó. A compactação de pós com formatos irregulares, leva à obtenção de material mais poroso, devido a aspectos relacionados com a baixa fluidez e consequiente baixo grau de preenchimento das cavidades do molde. Oh et al..$^{21,23,51}$ sintetizaram titânio puro compactado a partir de pó esférico com e sem aplicação de pressão, encontrando porosidades na faixa de 5 a $37 \%$. Estes valores podem ser aumentados para 35 a $50 \%$ pelo uso de pó com partículas irregulares, como aqueles produzidos por HDH. Neste caso, é importante fazer a escolha da faixa granulométrica a ser trabalhada, uma vez que a compactação de um pó com uma faixa granulométrica muito extensa, fará com que partículas menores se 


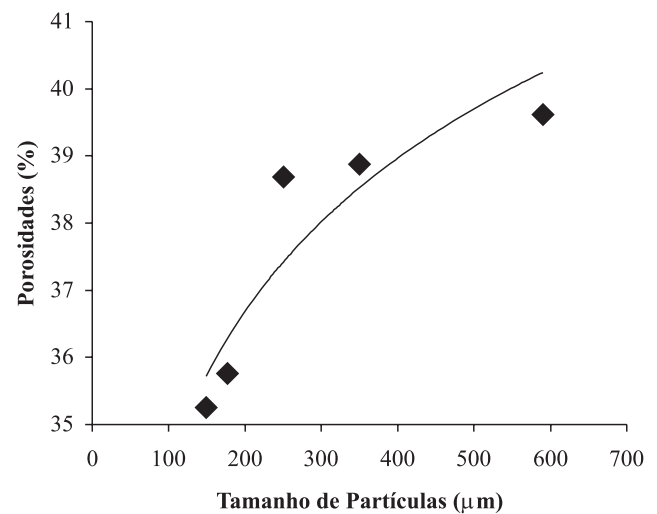

Figura 2. Variação da porosidade de compactos de titânio puro em função do tamanho médio das partículas do pó utilizado na compactação

acomodem entre os espaços vazios deixados pelas partículas maiores, densificando o material além do desejado. Assim, com o intuito de evitar tal problema, o pó obtido por HDH foi peneirado e sua faixa granulométrica determinada. Com a finalidade de se obterem compactos com porosidade controlada, amostras do pó com tamanho médio de partículas de 88, 177, 250, 350 e $590 \mu \mathrm{m}$ foram prensadas uniaxialmente a $110 \mathrm{MPa}$ e sinterizadas a $1200{ }^{\circ} \mathrm{C} \mathrm{em}$ vácuo de $10^{-7}$ Torr. As densidades relativas foram determinadas geometricamente e os resultados encontrados são mostrados no gráfico da Figura 2, no qual se verifica a porosidade como função do tamanho médio das partículas do pó utilizado para a obtenção dos compactos. As porosidades variaram entre 35 e $40 \%$, ficando evidente a tendência de crescimento da porosidade com o aumento do tamanho médio das partículas do pó.

A Figura 3 mostra as imagens MEV da superfície de dois destes compactos após sinterização, com aumento de 500 vezes, para os
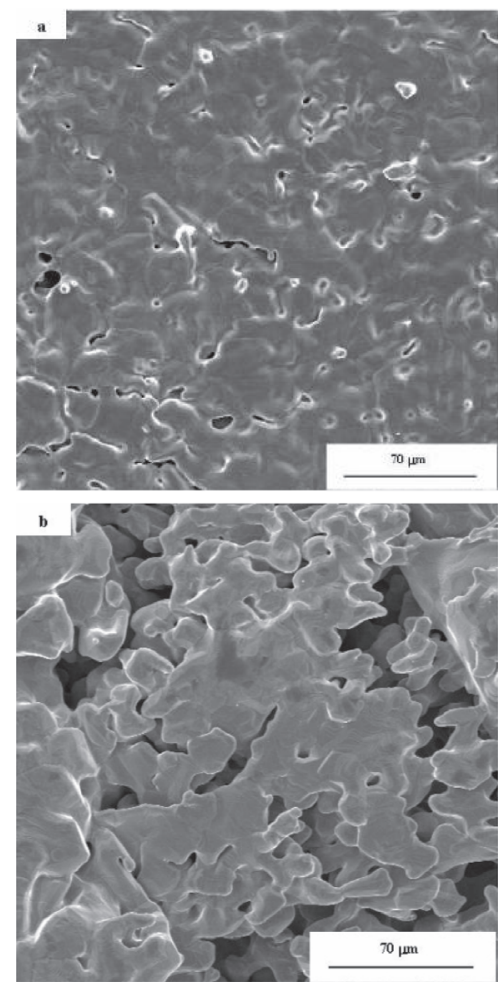

Figura 3. Imagens MEV dos compactos de titânio puro poroso pós-sinterização: a) compacto pouco poroso (tamanho médio de partícula do pó: $88 \mu \mathrm{m}$ ); b) compacto mais poroso (tamanho médio de partícula do pó: 590 m) compactos obtidos a partir de partículas com tamanhos médios de 88 e $590 \mu \mathrm{m}$. Verifica-se nitidamente a diferença na quantidade de poros em função da faixa granulométrica adotada.

A Figura 4 mostra o mesmo compacto apresentado na Figura 3b, em uma ampliação maior (3500 vezes). Tal ampliação permite verificar maiores detalhes na morfologia do poro e na superfície da amostra. Os poros formados são não-esféricos, apresentando cantos pontiagudos, o que é função da forma e do tamanho das partículas do pó. A formação deste tipo de poro é inerente à técnica da sinterização do pó. Os poros em segundo plano evidenciados nas Figuras 3 b e 4 mostram que a porosidade não se concentra apenas na superfície do compacto, mas se propaga para o interior do mesmo. Em relação à superfície, verifica-se que apresenta rugosidade superficial provavelmente decorrente da contração de volume durante a sinterização.

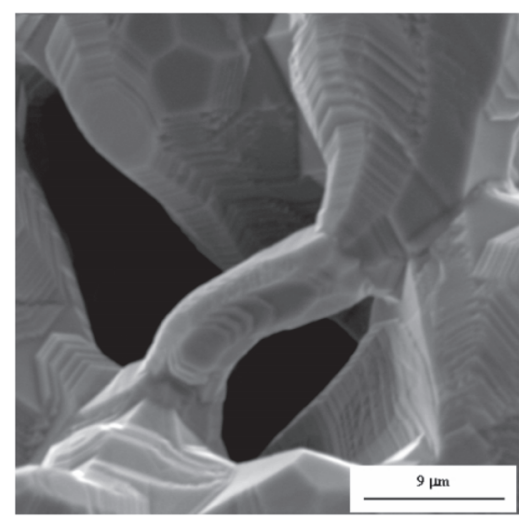

Figura 4. Imagens MEV evidenciando a morfologia do poro formado nos compactos de titânio

Dois outros aspectos são destacados nos trabalhos publicados na literatura a respeito de obtenção de titânio poroso por este método. O primeiro refere-se à constatação de que a porosidade diminui com o aumento da pressão de sinterização para uma mesma temperatura, o que é atribuído à deformação plástica. $\mathrm{O}$ segundo, refere-se à verificação de que as temperaturas de sinterização praticamente não afetam a densificação dos compactos de titânio, o que se contrapõe às situações nas quais são obtidos compactos densos.

\section{OUTROS MÉTODOS DE OBTENÇÃO DE TITÂNIO METÁLICO POROSO}

\section{Sinterização de pré-formas contendo um agente esparçante}

A técnica consiste basicamente em misturar o agente esparçante ao pó metálico, compactar a mistura e fazer um tratamento térmico. O tratamento térmico divide-se em duas etapas: na primeira, a pirólise, a amostra é aquecida até uma determinada temperatura necessária para a decomposição e retirada do esparçante e, na segunda, a sinterização, o pó é consolidado. A decomposição do agente esparçante produz, entre outras, substâncias gasosas, as quais são responsáveis pela formação dos poros, sendo estes formados durante a saída dos gases ${ }^{52-55}$.

A mistura de titânio em pó com o gás oriundo da decomposição do agente esparçante sólido produz: poros pequenos, que surgem entre as partículas do pó, também chamados de poros primários, e poros grandes pela presença do gás, chamados poros secundários. Durante a sinterização, os poros primários somem, devido aos processos de transporte de massa, ficando apenas os poros secundários. Como estes últimos mantêm o formato das bolhas do gás, a forma e 
a fração volumétrica dos poros neste processo são bem controladas, obtendo-se maior esfericidade. As porosidades atingem valores que variam entre 60 a $80 \%$. As desvantagens estão relacionadas com o excessivo tamanho dos poros secundários em comparação aos primários residuais, além das impurezas oriundas de ligantes e surfactantes que devem ser adicionados à mistura pó + gás.

Exemplos de agentes esparçantes sólidos são a carbamida $(\mathrm{NH})_{2} \mathrm{CO}$ e o bicarbonato de amônio $\left(\mathrm{NH}_{4}\right) \mathrm{HCO}_{3}$, os quais se decompõem, a temperaturas abaixo de $200{ }^{\circ} \mathrm{C}$, em componentes gasosos sem reagirem com o titânio. A uréia apresenta a desvantagem de decompor ao ar formando biureto sólido, contaminando o titânio. Por este motivo, as reações com uréia devem ser processadas sob vácuo. Por outro lado, a decomposição do bicarbonato de amônio ao ar é limpa, produzindo amônia, dióxido de carbono e água, os quais são facilmente eliminados durante o processo.

Wen et al. ${ }^{12}$ utilizaram partículas do dispersante bicarbonato de amônio misturadas ao pó de titânio para produzir compactos por prensagem uniaxial a $100 \mathrm{MPa}$. Os compactos verdes obtidos por esta técnica foram, então, tratados termicamente, atingindo porosidades de até $78 \%$. A estrutura obtida apresentou microporos isolados distribuídos nas paredes de macroporos interconectados. Os autores atribuíram a formação destes microporos à contração de volume que ocorre durante o processo de sinterização. As esponjas apresentaram ainda boas propriedades mecânicas expressas nos valores de tensão de compressão de $35 \mathrm{MPa}$ e módulo de Young de 5,3 Gpa. Utilizando carbamida como esparçante, em um processo muito próximo ao anteriormente descrito, Bram et al. ${ }^{54}$ sinterizaram esponjas com porosidades entre 60 e $77 \%$, obtendo valores de tensão de compressão de até $100 \mathrm{MPa}$.Outros agentes esparçantes têm sido utilizados como formadores de poros em processos similares aos descritos anteriormente. Como exemplo têmse os grânulos poliméricos ${ }^{56}$, os quais têm sido utilizados com a finalidade de se obter esponjas com alta porosidade e boas propriedades mecânicas. Apesar desta técnica originar compactos com alta porosidade, não promove um controle da forma dos poros, dependendo da homogeneização da mistura pó + titânio.

\section{Sinterização de pó depositado em uma matriz fugaz formada por macroporos}

Nesta técnica, é fabricado um molde com material polimérico ${ }^{57}$ de maneira que possua poros no formato desejado, tipo favo de mel, por ex.. O molde é então repetidamente recoberto com uma mistura de pós de titânio e ligante. Durante o tratamento térmico, o molde se decompõe e escapa, deixando em seu lugar espaços vazios que constituirão os poros no formato do mesmo. Ao final da sinterização é obtida uma estrutura formada de macroporos originados pelo molde e microporos originados pela sinterização do titânio que recobria a matriz. A esponja de titânio será formada por células abertas com estrutura altamente reticulada. Li et al..$^{58}$ utilizaram uma matriz polimérica de poliuretano para sinterizar pó da liga Ti-6Al-4V por este método, produzindo esponjas metálicas reticuladas com $88 \%$ de porosidade, as quais apresentaram tensão de compressão de $10 \mathrm{MPa}$.

Foram destacados, neste trabalho, os métodos de obtenção de titânio poroso baseados em processos que utilizam as etapas básicas da técnica da metalurgia do pó. Há na literatura, contudo, variações nos processamentos que fogem aos nossos objetivos.

\section{APLICAÇÕES}

Inúmeras são as aplicações para o titânio e seus compostos. Serão, contudo, apontadas aquelas referentes ao uso do titânio me- tálico, suas ligas e as esponjas metálicas, uma vez que são de grande interesse industrial por combinarem as excelentes propriedades dos metais, como força, tenacidade, deformabilidade e condutividades térmica e elétrica, com as vantagens estruturais, como leveza, dureza e elevada área superficial, dos materiais porosos. Destaca-se o uso deste metal na indústria e na área biomédica. Como matéria-prima para a indústria, o titânio é encontrado na forma de chapas, barras, tubos, varetas, folhas, placas, canos e peças semi-acabadas.

\section{Aplicações industriais}

\section{Aeroespacial e nanoaeroespacial}

Devido à sua baixa massa específica e excelentes propriedades mecânicas e resistência à corrosão, o titânio é utilizado na produção de estruturas que sejam ultraleves, que possam ser utilizadas a altas temperaturas, resistam a vibrações e a meios corrosivos. Assim, tem-se a presença deste metal como matriz de painéis tipo sanduíche, os quais compõem as estruturas de componentes das turbinas dos aviões, bem como as partes das asas, engrenagens e revestimentos, entre outros ${ }^{6-11}$. Verifica-se que a eficiência dos motores de turbinas a gás é substancialmente melhorada, apenas pelo uso de ligas de titânio em componentes como dispositivos mecânicos utilizados para produzir correntes de ar, gás ou vapor como as lâminas das pás de hélices, discos e partes não-rotoras. $\mathrm{O}$ principal ganho no uso do titânio está na alta razão força-peso, na possibilidade de uso destas ligas a altas temperaturas e à boa resistência aos problemas causados por esforços repetitivos. Atualmente, grande parte da estrutura dos aviões, como o Boeing F-4 ${ }^{59}$, é composta por titânio e suas ligas. Assim, pode-se encontrar este metal em grande parte da fuselagem central, nos estabilizadores das asas, na estrutura da fuselagem traseira, no revestimento traseiro, nas quilhas, nas garras da catapulta e nas portas de acesso ao motor. Atualmente, estão sendo fabricados Boeings ${ }^{60}$ cuja composição em termos de materiais compósitos é de $50 \%$, sendo $20 \%$ alumínio e $30 \%$ titânio, aço e outros materiais. Comparando estes com os $12 \%$ de materiais compósitos do Boeing 777, no qual a percentagem de alumínio é de $70 \%$ e de titânio, aço e outros de apenas $18 \%$, verifica-se o grande crescimento no uso do titânio neste setor.

Este metal é ainda utilizado na sustentação do "nariz" de mísseis guiados e no trem de pouso das aeronaves espaciais, a fim de prevenir o colapso destas partes causado pelas altas temperaturas locais atingidas pelos mesmos.

\section{Trocadores de calor}

Aplicações referentes ao uso ou desenvolvimento de trocadores de calor são uma das mais importantes para o titânio, principalmente quando o meio é a água, seja esta do mar, salobra ou poluída. $\mathrm{O}$ condensador e todas as partes estruturais do mesmo são usados extensivamente em plantas, refinarias, sistemas de ar-condicionado, plantas químicas, plataformas. Em todos estes casos, são constatadas a grande durabilidade e eficiência destes trocadores, pelo fato de não serem freqüentemente divulgadas falhas devido à corrosão no sistema de resfriamento. Algumas das aplicações dos trocadores de titânio são processamento de óleo térmico à alta temperatura, aquecedores de produtos químicos como solventes orgânicos, recuperadores de calor, trocadores de alta temperatura, evaporadores e condensadores para refrigeração com todos os tipos de refrigerantes ${ }^{61}$.

\section{Indústria química}

Devido à sua resistência à corrosão e ao ataque químico, o mercado de titânio para a indústria química está em fase de crescimento 
acelerado. Equipamentos como vasos, trocadores de calor, tanques, agitadores, tubulações, torres, etc..$^{62}$, podem ser feitos de titânio. No Brasil, equipamentos de titânio são normalmente empregados na fabricação de fibras de poliéster com produtos químicos, tais como acetaldeidos e ácidos utilizados neste processo. Várias soluções orgânicas e cloretos são mais eficientemente manuseados com titânio. A extrema resistência do titânio à corrosão em ambientes oxidantes, como ácido nítrico, ácido cítrico, em sais de bromo, de cloro, etc., pode dar origem a equipamentos muito mais eficientes que os atualmente utilizados. A indústria de papel e polpa utiliza-se de grandes quantidades de equipamentos de titânio para o alvejamento do papel branco. Para a industria de galvanoplastia são fabricados parafusos especializados, serpentinas, cestos, ganchos, gancheiras e chapas seletivas. Refinarias de petróleo utilizam titânio em trocadores de calor, condensadores, unidades de refrigeração de água salgada etc., e também nas cápsulas e seções das colunas de fracionamento. A extração de metais oriundos de minerais por hidrometalurgia em reatores de titânio constitui-se em uma alternativa de processos de fusão com baixo impacto ambiental. O tempo longo de vida, a alta eficiência de energia e o alto grau de pureza dos produtos obtidos são fatores que contribuem para o uso do titânio em eletrodos, eletrocristalização e eletrorefinamento de metais, como cobre, ouro, manganês e óxido de magnésio.

\section{Indústria naval}

No que se refere à indústria naval, o titânio é empregado como liga ${ }^{63}$ em equipamentos e estrutura de pequenas embarcações, navios e submarinos. Nos submarinos, por ex., este elemento está presente em válvulas, bombas, trocadores de calor, fuselagem, material do casco, sistemas de propulsão à água e sistema de tubulação. Além destas, o titânio é aplicado em plantas de dessalinização de água do mar onde, além das propriedades já mencionadas, a alta eficiência no processo de condensação faz do titânio o melhor para este fim no que se refere à relação custo-benefício.

\section{Indústria nuclear ${ }^{64}$}

É empregado na fabricação de recuperadores de calor em usinas de energia nuclear. Grandes quantidades de titânio estão sendo utilizadas em recipientes para estocagem de combustível e em turbinas para reprocessamento e geração de energia, a partir de combustíveis fósseis ou nucleares.

\section{Indústria bélica}

O titânio é empregado não apenas na fabricação de armamento leve, como também na fabricação de mísseis e peças de artilharia. Uma tecnologia emergente para a produção de artefatos e armamento pesado de titânio manufaturado, chamada "Laser Shock Peening", usa pulsos a laser de alta energia para impactar a superficície do metal, criando uma tensão compressiva residual que melhora sensivelmente as propriedades relacionadas à fadiga e à tenacidade ${ }^{65}$. O metal assim trabalhado é, então, utilizado em componentes como engrenagens de transmissão em helicópteros, engrenagens de turbinas e aterrissagem de aviões, tanques, veículos terrestres, etc., melhorando a eficiência operacional em combate.

\section{Indústria de produtos para consumo}

Por causa das propriedades relacionadas com a leveza e alta resistência mecânica, o titânio é utilizado na indústria para a obtenção de produtos para consumo, como produtos de arquitetura, produtos de aplicação doméstica como acessórios para banheiros, pratos, faqueiros, etc., bicicletas e equipamentos esportivos em geral, óculos, relógios, computadores, próteses médicas, filtros e, ainda, produção de suportes para fins gerais.

\section{Aplicações biomédicas}

Além das propriedades já citadas, a atoxidade do titânio confere ao mesmo excelente biocompatibilidade, a qual justifica a utilização deste metal como biomaterial ${ }^{14-25}$. É encontrado como constituinte de bombas de corações artificiais, marcapassos, parte de válvulas para coração, próteses dentárias e audiológicas e, ainda, em próteses e implantes de juntas e ossos.

O alto módulo de tensão de elasticidade do titânio faz com que não responda bem às solicitações mecânicas relacionadas com aplicações cíclicas de tensão, uma vez que não absorve bem a energia mecânica de tais solicitações. Por outro lado, materiais com baixo módulo, como o osso (10 a $30 \mathrm{Gpa})$, respondem bem a tais solicitações. Quando é feito um implante de titânio em substituição ao osso, surge uma tensão de blindagem devido à diferença entre os módulos de elasticidade destes materiais. Um recurso que tem sido utilizado para minimizar esta tensão é a utilização da técnica da metalurgia do pó para produzir titânio com alta porosidade como forma de reduzir o módulo de elasticidade $\mathbf{E}$ do metal e, assim, minimizar o "stress" causado em tais implantes ${ }^{23,25}$. Próteses de ossos humanos, seja na área dental ou ortopédica, são fabricadas com titânio poroso já há algum tempo. Contudo, recentemente, tem-se vislumbrado a melhor fixação deste metal ao osso quando o mesmo se encontra poroso. O titânio poroso tem sido usado para a fixação de ossos humanos porque a superfície porosa do metal contribui para a formação de uma ligação estrutural e funcional entre o osso e o implante. Outro fator importante é que este metal apresenta boa compatibilidade com os tecidos vizinhos, provendo estabilidade por longo tempo.

\section{CONCLUSÃO}

A metalurgia do pó tem demonstrado ser uma técnica eficiente na obtenção de compactos de titânio com porosidade controlada, uma vez que além de permitir o processamento deste metal ainda na fase sólida (sob temperaturas abaixo do ponto de fusão do mesmo), permite o domínio do grau de consolidação do pó, através do controle dos parâmetros de processamento. Compactos de titânio obtidos por esta técnica encontram vasta aplicação como materiais estruturais, tanto na indústria como na área biomédica, por apresentarem excelentes propriedades físico-químicas e mecânicas.

No CTA, a metalurgia do pó tem sido utilizada para o desenvolvimento de titânio puro e suas ligas, partindo de Ti puro comercial produzido na década de 60, quando, no auge do Projeto Titânio, o Brasil se tornou o único país na América Latina a produzir este metal. A sinterização de pré-formas permitiu, através do controle granulométrico e dos parâmetros de processamento do pó, obter substratos com porosidades diversas, os quais demonstraram a dependência da porosidade em relação ao tamanho médio inicial das partículas do pó.

Existem variações da técnica convencional da metalurgia do pó, as quais podem ser utilizadas na produção de titânio metálico poroso, agregando detalhes como um maior grau de porosidade ou, ainda, um maior controle no formato e tipo de poros às estruturas obtidas.

\section{REFERÊNCIAS}

1. Barksdale, J.; Titanium Its Occurence, Chemistry and Technology, $2^{\text {nd }}$ ed., The Ronald Press Company: New York, 1966.

2. Budinski, K. G.: Budinski, M. K.; Engineering Materials: Properties and Selection, $6^{\text {th }}$ ed., Prentice Hall: Ohio, 1999.

3. Williams, J. C.: Belov, A. F.; Titanium and Titanium Alloys Scientific and Technological Aspects, Plenum Press: Moscow, 1982.

4. Kimura, H.; Izumi, O.; Titanium '80: Science and Technology Aspects, The Metallurgical Society of AIME: Kioto, 1980. 
5. Lide, D. R.; Handbook of Chemistrty and Physics: A Ready-Reference Book of Chemical and Physical Data, 82 $2^{\text {th }}$ ed., CRC Press: Boca Raton, 2001.

6. Bhowmik, S.; Bonin, H. W.; Bui, V. T.; Weir, R. D.; Int. J. Adhes. Adhes. 2006, 26, 400 .

7. Bache, M. R.; Int. J. Fatigue 2003, 25, 1079.

8. Pornsin-sirirak, N. T.; Tai, Y. C.; Nassef, H.; Ho, C. M.; Sens. Actuators, A 2001, 89, 95

9. Bache, M. R.; Int. J. Fatigue, 1999, 21, 105.

10. Brewer, W. D.; Bird, R. K.; Wallace, T. A.; Mater. Sci. Eng., A 1998, 243, 299.

11. Boyer, R. R.; Mater. Sci. Eng., A 1996, 213, 103.

12. Froes, F. H.; Eylon, D.; Friedman, G. Em ASM Handbook; Eise, W. B.; Ferguson, B. L.; German, R. M.; Iacocca, R.; Lee, P. W.; Madan, D.; Moyer, K.; Sanderow, H.; Trudel, Y., eds.; $2^{\text {nd }}$ ed., Materials Park: Ohio, 2000, cap. 7, p. 748-755.

13. Weis, R. S.; Bania, P. J.; Eylon, D.; Semiatin, S. L.; Advances in the Science and Technology of Titanium Alloy Processing, TMS: Minerals, Metals, Materials \& Society: Warrendale, 1996.

14. Ryan, G.; Pandit, A.; Apatsidis, D. P.; Biomaterials 2006, 27, 2651.

15. Rack, H. J.; Qazi, J. I.; Mater. Sci. Eng., C 2006, 26, 1269.

16. Akahori, T.; Niinomi, M.; Fukui, H.; Ogawa, M.; Toda, H.; Mater. Sci. Eng., C 2005, 25, 248 .

17. Silva, H. M.; Schneider, S. G.; Moura Neto, C.; Mater. Sci. Eng., C 2004, $24,679$.

18. Eisenbarth, E.; Velten, D.; Müller, M.; Thull, R.; Breme, J.; Biomaterials 2004, 25, 5705

19. Liu, X.; Chu, P. K.; Ding, C.; Mater. Sci. Eng., R 2004, 47, 49.

20. Taddei, E. B.; Henriques, V. A. R.; da Silva, C. R. M.; Cairo, C. A. A.; Mater. Sci. Eng., C 2004, 24, 683.

21. Oh, I. H.; Nomura, N.; Masahashi, N.; Hanada, N.; Scr. Mater. 2003, 49, 1197.

22. Niinomi, M.; Sci. Technol. Adv. Mater. 2003, 4, 445.

23. Oh, I. H.; Segawa, H.; Nomura, N.; Hanada, S.; Mater. Trans. 2003, 44, 657.

24. Henriques, V. A. R.; da Silva C. R. M.; Key Eng. Mater. 2001, 89, 443.

25. Wen, C. E.; Mabuchi, M.; Yamada, Y.; Shimojima, K.; Chino, Y.; Asahina. T.; Scr. Mater. 2001, 45, 1147.

26. Shapavalov, V. I.; US Pat. 5,181,549 1979.

27. Shapavalov, V. I.; Boyko, L.; Adv. Eng. Mater. 2004, 6, 407.

28. Duarte, I.; Mascarenhas, J.; Ferreira, A.; Banhart, J.; Adv. Mater. Forum I Key Eng. Mater. 2002, 230, 96.

29. Lehmhus, D.; Banhart, J.; Rodriguez-Perez, M. A.; Mater. Sci. Technol. 2002, 18,474

30. Liu, P. S.; Liang, K. M.; Mater. Sci. Technol. 2000, 16, 575.

31. Liu, Y.; Chen, L. F.; Tang, H. P.; Liu, C. T. B.; Huang, B. Y.; Mater. Sci. Eng., A 2006, 418, 25.

32. Ueta, M. C. C.; Fracote, C. A.; Rodrigues, V. A.; Mater. Sci. Forum 2005, 498-499, 211.

33. Li, C. F.; Zhu, Z. G.; Chin. Phys. Lett. 2005, 22, 2647.

34. Bautista, A.; Moral, C.; Blanco, G.; Mater. Corros. 2005, 56, 98.
35. Krone, L.; Schuller, E.; Bram, M.; Hamed, O.; Buchkremer, H.P.; Stover, D.; Mater. Sci. Eng., A 2004, 378, 185.

36. Bewlay, B. P.; Gigliotti, M. F. X.; Hardwicke, C. U.; J. Mater. Process. Technol. 2003, 35, 324

37. Hu, Z. M.; Dean, T. A.; J. Mater. Process. Technol. 2001, 111, 10

38. Froes, F. H.; Eylon, D. Em ref.12, cap.7, p. 164-168.

39. Bocanegra-Bernal, M. H.; J. Mater. Sci 2004, 39, 6399.

40. Albero, J. L. A.; Cerâmica Industrial 2000, 5, 5.

41. Oliveira, I. R.; Studart, A. R.; Pillegi, R. G.; Pandolfelli, V. C.; Dispersão e Empacotamento de Partículas: Princípios e Aplicações em Processamento Cerâmico, Fazendo Arte: São Paulo, 2000.

42. Crolius, R.W.; Am. Ceram. Soc. Bull. 2005, 84, 9.

43. Panigrahi, B. B.; Godkhindi, M. M.; Das, K.; Mukunda, P. G.; Ramakrishnan, P.; Mater. Sci. Eng., A 2005, 396, 255.

44. Oh, I. H.; Nomura, N.; Masahashi, N.; Hanada, S.; Scr. Mater. 2003,49, 1197.

45. Eloff, P. C. Em ref. 12, cap.7, p. 393-395.

46. Henriques, V. A. R.; Cairo, C. A. A.; Silva, C. R. M. da; Resumos do $16^{\circ}$ Congresso Brasileiro de Engenharia e Ciências dos Materiais, Porto Alegre, Brasil, 2004.

47. Kroll, W. J.; J. Electrochem. Soc. 1940, 78, 35.

48. Hunter, M. A.; J. Am. Chem. Soc. 1910, 32, 330.

49. Cho, S. W.; Shim, G.; Park, J. S.; Met. Mater. Int. 2006, 12, 51.

50. Ricceri, R.; Arcuri, F.; Matteazzi, P.; J. Phys. IV France 2001, 11, 51.

51. Oh, I. H.; Nomura, N.; Hanada, S.; Mater. Trans. 2002, 43, 443.

52. Laptev, A.; Bram, M.; Buchkremer, H. P. Powder Metall. 2004, 47, 85.

53. Wen, C. E.; Yamanda, Y.; Shimojima, K.; Chino, Y.; Asahina, T.; Mabuchi, M.; Eur. Cells Mater. 2001, 1, 61 .

54. Bram, M.; Stiller, C.; Buchkremer, H. P.; Stover, D.; Baur, H.; Adv. Eng. Mater. 2000, 2, 196

55. Guo, Z. X.; Jee, C. S. Y.; Ozguven, N.; Evans, J. R. G.; Mater. Sci. Technol. 2000, 16, 776 .

56. Rausch, G.; Banhart, J. Em Handbook of Cellular Metals; Degischer, H. P.; Kriszt, B., eds.; Wiley: Weinheim, 2002, p. 21.

57. Kupp, D.; Claar, D.; Flemming, K.; Goehler, U. Em Processing and Properties of Lightweight Cellular Metals and Structures; Ghosh, A.; Sanders, T.; Claar, D., eds.; TMS: Warrendale, 2002, p. 61.

58. Li, J. P.; Lik De Groot, S. H.; Layrolle, P.; Key Eng. Mater. 2002, 51, 218.

59. http://www.boeing.com/defense-space/military/f4/images/titanium.htm, acessada em Setembro 2005.

60. http://www.boeing.com/commercial/7e7/programfacts.html, acessada em Setembro 2005.

61. http://www.tranterphe.com/phe/PDFs/UM-1A\%20Portuguese.pdf, acessada em Setembro 2005

62. http://www.titanium.com/, acessada em Setembro 2005.

63. Gorynin, I. V.; Mater. Sci. Eng., A 1999, 263, 112.

64. Marmy, P.; Leguey, T.; Belianov, I.; J. Nucl. Mater. 2000, 283, 602.

65. https://www.dodmantech.com/award/CY03/index.asp?main=award, acessada em Agosto 2005. 